\title{
A Risk Assessment Framework for Seed Degeneration: Informing an Integrated Seed Health Strategy for Vegetatively Propagated Crops
}

\author{
S. Thomas-Sharma, † J. Andrade-Piedra, M. Carvajal Yepes, J. F. Hernandez Nopsa, M. J. Jeger, R. A. C. Jones, \\ P. Kromann, J. P. Legg, J. Yuen, G. A. Forbes, and K. A. Garrett ${ }^{\dagger}$
}

First, fourth, and eleventh authors: Department of Plant Pathology, Kansas State University, Manhattan; first author: Department of Plant Pathology, University of Wisconsin-Madison, Madison; second author: International Potato Center, Lima, Peru; third author: International Center for Tropical Agriculture, Cali, Colombia; fourth and eleventh authors: Plant Pathology Department, Institute for Sustainable Food Systems, and Emerging Pathogens Institute, University of Florida, Gainesville; fifth author: Centre for Environmental Policy, Imperial College London; sixth author: Institute of Agriculture, University of Western Australia, Crawley, Australia; seventh author: International Potato Center, Quito, Ecuador; eighth author: International Institute of Tropical Agriculture, Dar es Salaam, Tanzania; ninth author: Department of Forest Mycology and Plant Pathology, Swedish University of Agricultural Sciences, Uppsala, Sweden; and tenth author: International Potato Center, Kunming, China.

Accepted for publication 1 May 2017.

\begin{abstract}
Pathogen buildup in vegetative planting material, termed seed degeneration, is a major problem in many low-income countries. When smallholder farmers use seed produced on-farm or acquired outside certified programs, it is often infected. We introduce a risk assessment framework for seed degeneration, evaluating the relative performance of individual and combined components of an integrated seed health strategy. The frequency distribution of management performance outcomes was evaluated for models incorporating biological and environmental heterogeneity, with the following results. (1) On-farm seed selection can perform as well as certified seed, if the rate of success in selecting healthy plants for seed production is high; (2) when choosing among within-season management strategies, external inoculum can determine the relative usefulness of 'incidence-altering management' (affecting the proportion
\end{abstract}

ABSTRACT of diseased plants/seeds) and 'rate-altering management' (affecting the rate of disease transmission in the field); (3) under severe disease scenarios, where it is difficult to implement management components at high levels of effectiveness, combining management components can be synergistic and keep seed degeneration below a threshold; (4) combining management components can also close the yield gap between average and worst-case scenarios. We also illustrate the potential for expert elicitation to provide parameter estimates when empirical data are unavailable.

Additional keywords: banana, cassava, environmental heterogeneity, positive selection, potato, root crops, seed degeneration, seed health, simulation models, sweetpotato, tuber crops, vegetative propagation, yam.
In vegetatively propagated crops, pathogens tend to accumulate if planting material is drawn from within a crop population over multiple generations, resulting in significant quality and yield losses. This problem, termed seed degeneration (where 'seed' refers to vegetative planting material), occurs commonly when certified, disease-free planting material is scarce and/or expensive, as is the case in many low-income countries (Gibson and Kreuze 2014; Thomas-Sharma et al. 2016) and for some specialty crops (Gergerich et al. 2015). An integrated seed health strategy (Thomas-Sharma et al. 2016) is needed to address seed degeneration, drawing on management components that are currently available to farmers, or can be made available in the near future. We present a risk assessment framework for seed degeneration in vegetatively propagated crops, designed to support the development of strategies for integrating management components.

Seed degeneration is affected by many biophysical factors such as the susceptibility of a variety, the abundance of alternative hosts (e.g., weeds), the roles and efficiencies of vectors, regional inoculum availability, and the conduciveness of weather to disease

†Corresponding authors: K. A. Garrett; E-mail address: karengarrett@ufl.edu, and S. Thomas-Sharma; E-mail address: thomasuga@gmail.com

*The $e$-Xtra logo stands for "electronic extra" and indicates that three supplementary material files are published online. development and spread. Reversion, where seed obtained from infected mother plants is healthy, can reduce seed degeneration in sweetpotato (Gibson et al. 2014), potato (Bertschinger 1992), and cassava (Fargette et al. 1996; Gibson and Otim-Nape 1997). The etiology of seed degeneration is often specific to a crop and geographic region. Cassava mosaic geminiviruses (CMGs) and Cassava brown streak viruses (CBSVs) are major causes of degeneration in East Africa (Legg et al. 2015), while viruses associated with cassava frogskin disease are the main causes of degeneration in South America (Carvajal-Yepes et al. 2014). For potato, viruses are a major cause of seed degeneration around the world (Thomas-Sharma et al. 2016), while latent tuber infections of the bacterial wilt pathogen, Ralstonia solanacearum, are a major problem in tropical and subtropical countries (Mwangi et al. 2008), and the fungal pathogen Rhizoctonia solani is a problem at high altitudes in the Andes (Fankhauser 2000).

The use of seed certified to be disease-free or certified to have disease levels below a threshold (hereafter referred to as certified seed) is often recommended as the primary management strategy to counter on-farm seed degeneration (Frost et al. 2013; Gergerich et al. 2015; Thomas-Sharma et al. 2016). Examples of such formally regulated systems include the U.S. National Clean Plant Network (nationalcleanplantnetwork.org), which supplies seed material for many fruit crops, the Wisconsin Seed Potato Improvement Association (www.potatoseed.org), which supplies seed potato in Wisconsin, U.S.A., and the Netherlands General Inspection Service for Agricultural Seeds and Seed Potatoes (www.nak.nl), which certifies seed potatoes from the Netherlands for global export. 
However, such specialized programs are rarely used by smallholder farmers in low-income countries (Thiele 1999; Thomas-Sharma et al. 2016). In many low-income countries, 80 to $95 \%$ of seed is routinely obtained from informal seed sources with poor or unknown seed health status (Mallowa et al. 2006; McGuire and Sperling 2016; Thomas-Sharma et al. 2016). Thus, one focus for the application of this new risk assessment framework is the context of low-income countries, especially food-security crops such as banana and plantain, cassava, potato, sweetpotato, and yam.

Seed degeneration can be managed by using components such as: certified seed; host resistance; roguing (removal of symptomatic plants from the field); selection of asymptomatic/leastsymptomatic seed, cuttings or plants as the seed source each season (referred to as seed selection); and management of vectors, pathogens, and alternative hosts (Blomme et al. 2014; Legg 1999; Thomas-Sharma et al. 2016). Grouping management components can facilitate decision-making and generalization of results. Berger (1997) grouped management components as those reducing initial inoculum, rate of disease spread, and time of exposure of the crop, while Jones (2006) grouped management components based on their selectivity against pathogens and whether they manage internal or external inoculum sources. We group management components as incidence- and rate-altering management components, a logical distinction based on the structure of our models. Incidence-altering management components affect the availability of inoculum from host material in the field (e.g., roguing) or seed lot (e.g., use of certified seed or seed selection). Ratealtering management strategies affect the rate of spread of disease in a field, e.g., use of host resistance and vector or pathogen management. Management of alternative host species could be treated as reducing inoculum availability from hosts, or as reducing the rate of spread, depending on the goals of an analysis. Potential synergies from combining management components (within or between groups) can be evaluated as reductions in disease, or increases in yield, that are greater when management components are combined compared with the sum of the individual component effects.

The importance of seed degeneration and the high cost of multiyear field experiments to support empirical analyses have motivated several studies using analytical and simulation models to better understand the process of seed degeneration. Several of these studies have focused on management strategies for cassava diseases, and vector dynamics (Fargette and Vie 1995; Holt et al. 1997), illustrating how small management improvements can reduce the risk that a cropping system approaches a threshold for rapid disease increase. Symptom-based management like roguing and seed selection can have variable success rates from one season to the next due to the effect of weather on symptom expression (Gibson and Otim-Nape 1997) and/or the level of farmer skill in identifying symptoms. McQuaid et al. (2016) evaluated the likely performance of roguing for cassava brown streak disease (CBSD) in seed multiplication sites, showing the potential in sites with low disease pressure. In a more general modeling study, van den Bosch et al. (2007) found that management components such as in vitro propagation, high accuracy cutting selection, and use of tolerant varieties can inadvertently select for virus strains that build up a high titer in host plants. New analysis of how strategic integration of management components enhances management performance can build on these studies.

Weather is a critical factor determining the rate of seed degeneration. Viral degeneration of seed potato is lower at high altitudes (Rahman and Akanda 2008), due at least in part to lower virus and vector activity (Fankhauser 2000), and higher rates of reversion or lower autoinfection efficiency (Bertschinger 1992). In a fine-scale forecasting model of potato viruses, Bertschinger et al. (1995) used daily temperature measurements to determine host growth rates and vector dynamics, predicting the number of infected progeny seed. In most other models of seed degeneration, however, weather is implicitly addressed in vector dynamics, and weather variability is rarely considered. Understanding the effect of seasonto-season weather variability is important for evaluating seed degeneration risk, and understanding climate change scenarios, e.g., where increased population growth of potato virus vectors is predicted for summer crops in parts of South Africa (van der Waals et al. 2013).

The limited data available related to the extent and variability of management component adoption, especially in scenarios where seed degeneration is a problem (e.g., low-income countries), can be a challenge for model parameterization. Studies generally report small-scale, site-specific estimates, so there is little information to guide scaling up consideration to regional or larger extents. In many applications where decisions have to be made despite severe data limitations, such as conservation biology, the use of expert opinion to fill information gaps has gained momentum (Mac Nally 2007; Martin et al. 2005; Yamada et al. 2003). 'Expert elicitation' is the systematic collection of the wealth of information integrated into scientists' opinions through the course of their studies of particular systems (Knol et al. 2010). Use in plant pathology has generally been limited to applications such as the use of expert knowledge for cluster sampling of disease incidence (Hughes and Madden 2002). We explored expert elicitation as a tool to provide the frequency distribution of likely parameter values (such as the level of disease resistance deployed) in India and Africa, along with information about the uncertainty due to lack of knowledge about these systems. Because expert elicitation can provide information about the deployment of a management component across farms in a region, the data it provides can be used to scale up model results to evaluate regional management performance.

We develop here a general risk assessment framework for seed degeneration, designed to inform an integrated seed health strategy for vegetatively propagated crops (Thomas-Sharma et al. 2016). There are many potential goals for model development, such as providing a good approximation to reality, precise predictions, or general insights into a phenomenon. Typically, models will compromise one of these objectives in the pursuit of others (Gross 2013; Levins 1966). Our goal in developing this framework is to provide a general assessment of the performance of different management approaches, as well as a framework that can be adapted to applications for specific pathosystems. The objectives of the study were to (1) build on current theoretical understanding of seed degeneration by including stochasticity of both environmental factors and management components, (2) evaluate scenarios where integrated seed health strategies would be more successful and less successful, and (3) explore the use of expert elicitation as a method to complement traditional empirical data.

We used the framework to ask a set of key questions. (1) Certified seed use is sometimes viewed as a "silver bullet" for managing seed degeneration, yet is unavailable to many farmers. For what scenarios can on-farm management perform as well as certified seed use, and when is certified seed use of little value without onfarm management? (2) The resource limitations of many farmers in low-income countries may force them to choose among withinseason management components. Which management components would perform better in the presence or absence of external inoculum and therefore be the better epidemiological choice? (3) When there are challenges for achieving high levels of effectiveness of implementation (e.g., due to cryptic symptoms or lack of farmer experience), can combining management components reduce the minimum effectiveness of implementation required for successful seed degeneration management? (In this study, 'effectiveness' refers to the effectiveness of implementation of a management component, such as the degree of disease resistance, and is differentiated from the effect of management on yield, termed management 'performance'.) (4) In a development context, the focus may lie not only on the average performance of strategies, 
but also on the tail of the frequency distribution of performance. Using the stochastic model, we evaluate how management can be modified to reduce losses to the farmers who may be experiencing least benefit from strategies.

\section{MATERIALS AND METHODS}

Overview. Purpose. We address seed degeneration, defined as pathogen buildup in seed material (Thomas-Sharma et al. 2016). This risk assessment framework for seed degeneration is designed to be broadly applicable to vegetatively propagated crops/pathosystems and to capture the key seasonal dynamics of seed degeneration (Fig. 1). The focus of the model is on biophysical factors affecting seed degeneration, while socioeconomic factors that might influence the efficacy of management are only addressed implicitly. While this is not an agent-based model, we generally followed a model description format recommended for agent-based models (Grimm et al. 2010), to enhance clarity and reproducibility. An interactive interface (http://www.garrettlab.com/shiny-seed-degen-model/), built by Y. Xing and S. Thomas-Sharma using the Shiny package in R, allows users to experiment directly with the models described here, by accessing the code used in this analysis.

Scales and state variables. The model time-step is a season $(s)$, defined as a 'vegetative generation', i.e., the time between planting and seed collection. For crop species where seeds are collected on a different time scale than harvest of the food crop (e.g., banana or sweetpotato), the production of seed (e.g., banana suckers and sweetpotato vines) and the production of food (e.g., fruit and storage roots) can be considered separately. Seed degeneration is modeled in an individual field without spatially explicit structure, over multiple seasons. Plant and seed populations are characterized by the number or proportion of healthy and diseased individuals, determining the resulting yield loss each season. The state variables are healthy $\left(\mathrm{HP}_{s}\right)$ and diseased $\left(\mathrm{DP}_{s}\right)$ plant numbers, healthy $\left(\mathrm{HS}_{s}\right.$ and $\mathrm{pHS}_{s}$ ) and diseased ( $\mathrm{DS}_{s}$ and $\mathrm{pDS}_{s}$ ) seed numbers and proportions, end of season yield $\left(\mathrm{Y}_{s}\right)$, and end of season percent yield loss $\left(\mathrm{YL}_{s}\right)$ (Table 1).

Process overview and scheduling. The model includes five processes that occur every season: host infection, host removal, seed formation, seed selection, and seed choice (Fig. 1). The effects of the following management strategies are evaluated: use of certified seed, host resistance, roguing, seed selection, and vector or pathogen management. (Management of alternative host species could be evaluated explicitly by incorporating an additional model component, or implicitly as part of the effects of vector or pathogen management.)

1. Host infection, or disease transmission, increases disease incidence in the field, and is a function of the disease incidence in the seed and the availability of external inoculum. The rate of disease transmission is determined by the maximum seasonal disease transmission, the degree to which weather conditions are disease-conducive, any external inoculum present, and the levels of host resistance and vector or pathogen management applied in

TABLE 1. State variables monitored in seed degeneration risk assessment framework

\begin{tabular}{ll}
\hline State variable & \multicolumn{1}{c}{ Description } \\
\hline $\mathrm{HP}_{\mathrm{s}}$ & Number of healthy plants in field, end of season \\
$\mathrm{DP}_{\mathrm{s}}$ & Number of diseased plants in field, end of season \\
$\mathrm{HS}_{\mathrm{s}}$ & Number of healthy seed, produced end of season \\
$\mathrm{DS}$ & Number of diseased seed, produced end of season \\
$\mathrm{pHS}_{\mathrm{s}}$ & Proportion of healthy seed, used in following season \\
$\mathrm{pDS}_{\mathrm{s}}$ & Proportion of diseased seed, used in following season \\
$\mathrm{Y}_{\mathrm{s}}$ & Absolute units of yield, end of season \\
$\mathrm{YL}_{\mathrm{s}}$ & Percentage yield loss, end of season \\
\hline
\end{tabular}

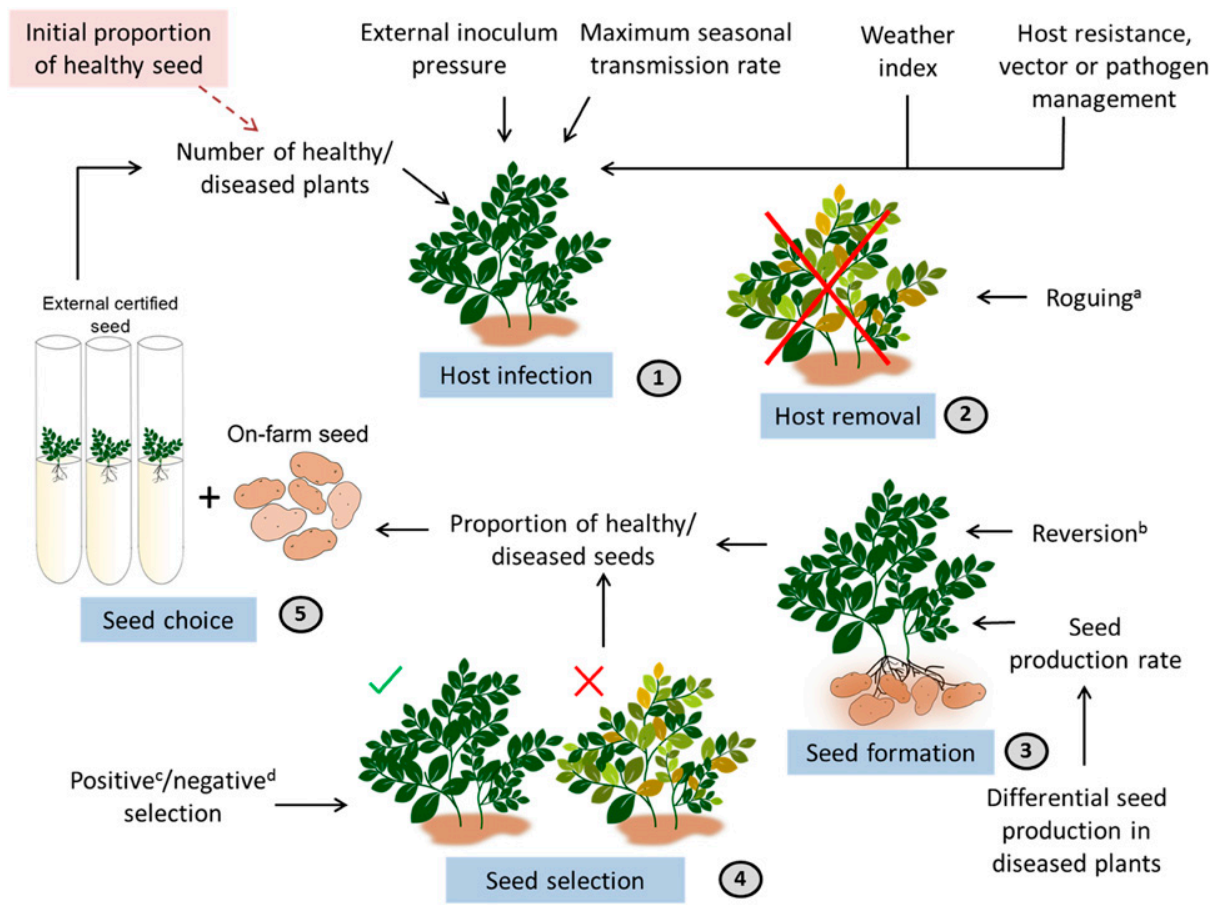

Fig. 1. Processes modeled in the seed degeneration risk assessment framework (with potato as an example) are (1) host infection (disease transmission), (2) host removal, (3) seed formation, (4) seed selection, and (5) seed choice. Rate-altering management components (host resistance, vector, or pathogen management), incidence-altering management components (seed selection, certified seed usage, and roguing), and phenomena such as reversion and differential seed production in diseased plants modify these processes. The rate of disease transmission is determined by how disease-conducive weather conditions are (included as a 'weather index'), external inoculum present, the maximum seasonal transmission rate, and any rate-altering management components. In the first season (time-step), the initial proportion of healthy seed used is provided, after which other processes and phenomena are introduced in the order depicted by the circled numbers. ${ }^{a}$ Removal of diseased plants from the field. ${ }^{\mathrm{b}}$ Production of disease-free seed by infected mother plant. ${ }^{\mathrm{c}}$ Selection of asymptomatic plants for seed under high disease intensity. ${ }^{\mathrm{d}}$ Rejection of symptomatic plants for seed under low disease intensity. 
the field. A subset of analyses highlight the greater impact of early-season infections compared with late-season infections. Good proxies for the level of external inoculum are challenging to obtain; in this framework, we included external inoculum as a factor that acts comparably to the presence of infected plants within the field.

2. Host removal occurs by roguing, where diseased plants are removed from the population (death due to disease is treated as minimal). In a subset of analyses, where early- and lateseason infections are considered, we also highlight the effects of roguing conducted early versus late in the season. Specifying a minimum yield $(\min Y)$ greater than zero supports analysis of the yield penalty due to roguing (when diseased plants produce usable yield). Any compensatory yield effects when roguing is applied (when surrounding plants compensate for yield loss; Salazar 1996) have not been included in the model.

3. We use the term 'seed formation' to describe the production of seed, where the health of the mother plant determines the health of the seed. During seed formation, reversion causes a proportion of diseased plants to become disease-free, producing healthy seed. Diseased plants may produce less seed, contributing less diseased seed to the total on-farm seed produced.

4. Seed selection is represented by a change in the proportion of diseased seed produced as a result of selecting against diseased plants as the seed source each season. We do not explicitly include a distinction often made in seed selection, between positive selection (selection of asymptomatic plants for seed under high disease intensity) and negative selection (rejection of symptomatic plants for seed under low disease intensity). In this model, the proportion of diseased seed is reduced, which might be due to either positive or negative selection.

5. Seed choice affects the proportion of on-farm seed that is combined with certified seed and used in the next season. The model is not spatially explicit, so potential effects from the degree of mixing among all seed planted in the field are not included. Often, farmers may choose to plant a mixture of healthy and infected seed when healthy seed is limited and reversion possible (Holt et al. 1997).

Design concepts. Stochasticity. Two general components are stochastic in this model: seasonal weather-conduciveness for disease, and the effectiveness with which management strategies (vector or pathogen management, seed selection, and roguing) are implemented. The parameters describing these components are the proportional effect of environment as a weather index $(W)$, the proportional change in infection rate due to vector or pathogen management $(M)$, the proportional selection against diseased seed $(Z)$, and the proportion diseased plants remaining after roguing $(A)$. Each of these follows a normal distribution truncated between 0 and 1. The normal distribution was selected because of the ease of interpreting the levels of variability and their effects (described below). Realizations below 0 were treated as 0 , and realizations above 1 were treated as 1 . (A beta distribution could likewise be used to describe the distribution, where selecting equivalent shape parameters for the beta distribution would provide a symmetric distribution in the interval $[0,1]$.)

For the weather index, the mean represents mean climatic conditions, and variation around the mean represents season-toseason variability in conduciveness to disease. For vector or pathogen (or alternative host) management, the mean represents mean effectiveness with which practices are applied and stochasticity represents season-to-season variability, due to timing of application or incomplete control (e.g., differences in the timing and choice of insecticides for vector management). For management practices based on symptom recognition (roguing and seed selection), the mean indicates the mean effectiveness with which the practice is applied during a season. Stochasticity represents both variability in symptom expression (e.g., due to variability in timing of infection among seasons, or delayed symptom development) and variability in farmers' skill in recognizing symptomatic plants. Thus, stochasticity in these analyses generally represents what Oberkampf et al. (2004) refer to as 'aleatory uncertainty'. Similar analyses could also be interpreted in terms of 'epistemic uncertainty' or uncertainty due to lack of system knowledge (Oberkampf et al. 2004), or a combination of these two types of uncertainty.

Calibration and rate of disease transmission: We conceptualize $\beta$ as the maximum rate of disease transmission during the growing season, associated with a scenario where there are no limiting factors for disease spread (i.e., when there is no vector or pathogen management, a highly susceptible host is planted, and the weather is highly disease-conducive). This rate is not necessarily intuitive, because it is multiplied by the number of diseased and healthy plants, in addition to being modified by parameters reflecting the effects of vector or pathogen management, host resistance, and weather. $\beta$ is determined by vector and pathogen attributes and other dispersal characteristics, and is interpreted in this general framework as reflecting the maximum rate in the absence of limiting factors. In most simulation experiments, we took $\beta=0.02$ as the maximum disease transmission rate per season. The effect of changing $\beta$ is the same as the effect of changing the other parameters $(W, H$, and $M$ ) that alter the rate. By choosing $\beta=0.02$ we obtained a range of disease outcomes for evaluation. Identifying a value of $\beta$ through this type of calibration met the needs of our general analysis. However, when developing a more precise application of this framework for managing a specific crop, calibrating $\beta$ for the pathosystem and relevant environments will be a key step.

Observations. Model output for a given parameter combination includes summary statistics (mean, 5th percentile, and 95th percentile) for the state variables, and timing for renewal with certified seed, i.e., the first time point at which the proportion of healthy seed falls below a threshold value, where a threshold proportion of 0.7 was used in examples.

Details. Initialization. The initial proportion of healthy seed $\left(p H S_{0}\right)$ determines the starting infection level in the field, in the first time-step. A relatively low proportion initial infection (0.2) was assumed in most scenarios, and in some cases was compared with a high proportion infection $(0.8)$. Such high pathogen incidence in planting material is a common scenario in low-income countries where farmers routinely use seed of poor health status (Gildemacher et al. 2009), or fields have high disease incidence, making it difficult to select disease-free planting material (Legg 1999).

Input data. The current application of the model does not depend on external weather data. However, for more specific applications, the weather index parameter could be defined as a function of a set of observed weather variables relevant to a particular pathosystem.

Submodels. There are four submodels that incorporate the effects of weather and management on the state variables, where state variables are defined in Table 1, parameters are defined in Table 2, and details are provided in Supplementary Material S1. The first submodel determines the number of healthy and diseased plants at the end of a season as a function of the starting plant population, proportion of healthy seed used for planting, rate of host infection, and rate of roguing. The second submodel determines the quantity of healthy and diseased seed produced as a function of the rate of seed production, reversion, differential seed production, and seed selection. The third determines yield and yield loss (in terms of food production) as a function of the proportion of diseased plants, the minimum and maximum yields, and rate of yield decline. The fourth determines the proportion of healthy seed used in the next season as a function of seed produced and proportion certified seed used.

Simulation experiments. Simulation experiments were implemented in the $\mathrm{R}$ programming environment ( $\mathrm{R}$ Core Team 2016). Experiments were designed to evaluate the effect of 
environment, and individual or combined management strategies on yield loss due to seed degeneration, to address the questions posed in the introduction. Each parameter combination was evaluated in 2,000 simulations. The maximum $(\max Y)$ and minimum $(\min Y)$ attainable yields were set at 100 and 0 units, respectively. Some parameters were evaluated at contrasting levels, while other parameters were set to the default values in Table 2 when their effects were not being evaluated. For example, parameters representing management practices were set to minimum values, without stochasticity, unless the impact of different levels of effectiveness of implementation was being evaluated. The default values of parameters were selected such that contrasting outcomes could be evaluated. All results are represented such that 0 indicates lack of a management component and 1 indicates complete effectiveness of implementation. (The effects of roguing, seed selection, vector management, and host resistance are thus described in the results in terms of the effectiveness of implementation, rather than in terms of their corresponding parameter definitions in the model [Table 2]). The standard deviation for stochastic variables was set to 0.3 and 0.1 for high and low variability scenarios, respectively. Short- (5 season) and longterm (10 season) effects on yield loss were studied.

Parameterization based on expert elicitation. The risk assessment framework described to this point is designed to evaluate risk at a particular field, given the environment and management decisions implemented. Expert elicitation was used to assess the adoption rates for individual management components by farmers in a region, as a first step toward scaling up individual farm risk assessments. In total, 25 experts (across crops and geographic regions) provided estimates of the frequency with which different

TABLE 2. Parameters used in seed degeneration risk assessment framework

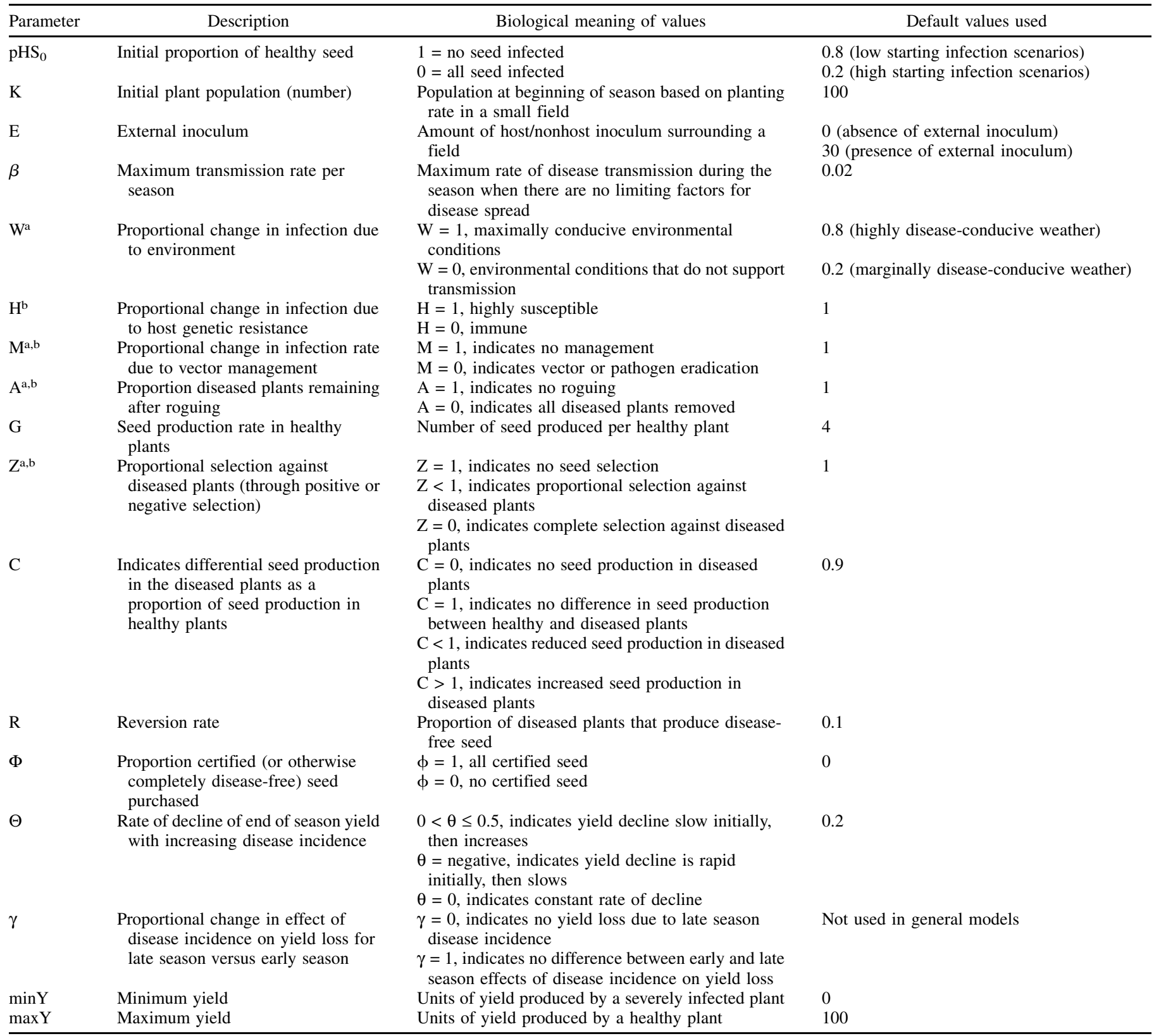

${ }^{a}$ For the stochastic parameters $\mathrm{W}, \mathrm{M}, \mathrm{Z}$, and $\mathrm{A}$, table entries indicate means, and standard deviations 0.1 and 0.3 were used to represent low and high variability scenarios, respectively.

${ }^{b}$ When addressing results, we describe and discuss these management effects in terms of the effectiveness of management implementation, so that all types of management can be considered with 1 indicating complete effectiveness of implementation and 0 indicating complete ineffectiveness. In contrast, for $\mathrm{H}$, $\mathrm{M}$, A, and $\mathrm{Z}$, the model and code are constructed such that 1 indicates no limiting factor for infection processes. 
management components were implemented with a particular level of effectiveness. For example, experts estimated the field acreage in each of 10 disease resistance categories in regions of Africa and India. The seed degeneration model described above was used to evaluate outcomes for an individual field, providing the frequency of potential outcomes for a given scenario defined by a set of parameter values. To supplement individual field evaluation, the expert elicitation data provide estimates of the frequency with which different scenarios occur. The data from expert elicitation were used to partially calibrate the frequency distribution of yield loss in the risk assessment framework for seed degeneration. Expert elicitation provided relatively high-confidence information about the frequency with which farmers used particular management techniques, but did not provide high-confidence estimates related to underlying transmission rates (because of the inherent difficulty in estimating transmission rates from personal observations). Thus, expert elicitation made this general analysis relatively more realistic, by indicating how likely different scenarios were to occur, but did not provide a precise estimate of yield outcomes. The details of the methods employed in expert elicitation are in Supplementary Material S2.

\section{RESULTS}

Effect of weather on long-term yield loss. The effect of disease-conducive weather conditions on long-term yield loss was first illustrated in the absence of management, and external inoculum, with other parameters set to default values. As expected, highly disease-conducive weather causes yield loss to rise quickly, while under marginally disease-conducive weather, it rises relatively more slowly and has the potential to stay at an acceptable level (Fig. 2). Season-to-season variability in weather causes seasonal fluctuations in yield loss. Under marginally diseaseconducive weather, this variability can cause long-term yield reductions to be very high and comparable to those in highly disease-conducive weather conditions.

Effect of individual management practices on yield loss. The effect of individual management practices on short-term yield loss varies with the degree to which weather is disease-conducive (Fig. 3). As disease conduciveness increases, management practices provide less reliable yield loss reduction. For all cases illustrated, under highly disease-conducive conditions, yield loss reaches nearly $100 \%$ when the proportional effectiveness of implementation of management practices is low (0 to 0.2$)$. The effects of the incidence-altering management practices such as roguing, seed selection, and certified seed use are similar to each other. As expected based on the model structure, rate-altering management strategies, such as vector or pathogen management and host resistance, had the same outcome for a given effectiveness of implementation (not shown separately).

In the absence of external inoculum, strategies such as roguing, use of certified seed, and seed selection could substantially reduce yield loss when implemented at 0.2 to 0.4 proportional effectiveness, under marginally disease-conducive conditions (Fig. 3). Ratealtering management strategies, however, required higher levels of proportional effectiveness of implementation ( 0.4 to 0.6$)$ to provide a comparable effect on yield loss. Even when rate-altering management strategies were implemented at 'complete' proportional effectiveness (i.e., at 1), in marginally disease-conducive weather conditions, a low level of yield loss $(\sim 10 \%)$ was observed (Fig. 3A). This was because it took more than five seasons for ratealtering management to reduce yield loss levels to zero (data not shown). Depending on weather conduciveness and resistance levels, management practices such as roguing, use of certified seed, and seed selection were thus 20 to $40 \%$ more beneficial than rate-altering management strategies, in the absence of external inoculum (Table 3).

When external inoculum is present, however, incidence-altering management was less successful than rate-altering management strategies, reversing the ranking observed in the absence of external inoculum (Fig. 4A, B). When both seed selection and vector or pathogen management were implemented at 0.6 proportional effectiveness, the use of vector or pathogen management in the presence of external inoculum (Fig. 4D) resulted in a relatively slower increase in long-term yield loss compared with seed selection (Fig. 4C).
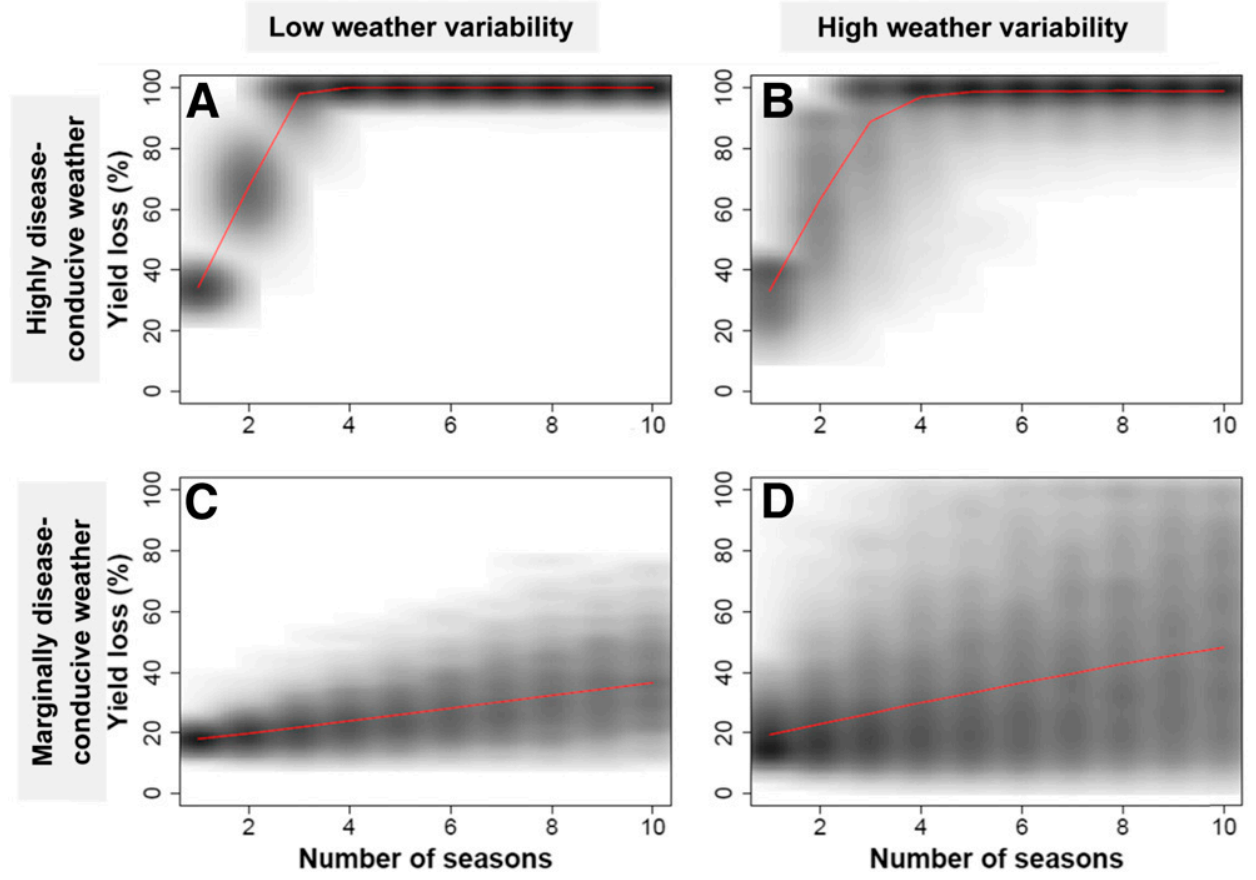

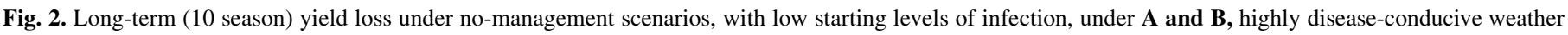

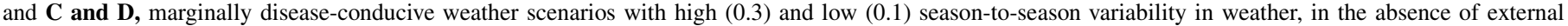
inoculum (based on 2,000 simulations). Other parameters are set to default values in Table 2 . Red lines indicate the mean value. 
Effect of combining management strategies on yield loss. The minimum level of effectiveness of implementation for a management component to keep long-term yield loss below $10 \%$ (in the absence of external inoculum) changed with the level of resistance used (Table 3). Under highly disease-conducive weather conditions, when susceptible varieties were grown, vector or pathogen management, roguing, seed selection, and external certified seed had to be used at $0.9,0.7,0.7$, and 0.6 proportional effectiveness, respectively, to maintain yield loss $<10 \%$. If a resistant variety was used, however, this minimum effectiveness of implementation could be lowered (Table 3). In scenarios where starting infection is high and weather is highly conducive for disease, seed selection is insufficient to keep yield loss below $10 \%$ in susceptible varieties (data not shown).

Combining management strategies is also useful to delay the need for seed renewal from off-farm certified sources (Table 4). Consider a scenario where renewing seed material with off-farm certified seed becomes necessary when the healthy seed proportion falls below a threshold of 0.7 (which corresponds to approximately 30 to $40 \%$ yield loss depending on conduciveness of weather). In the presence of external inoculum and highly disease-conducive weather conditions, seed renewal was necessary every season when seed selection and vector or pathogen management were practiced individually, but when these practices were combined, seed renewal was not necessary for $\sim 12$ seasons. In this case, there was strong synergy in the sense that the time to seed renewal for the combined management was substantially larger than the sum of the times to renewal for the two components individually.

Effect of season-to-season variability in weather and management practices. Under high proportional effectiveness of implementation $(>0.8)$, high season-to-season variability in vector or pathogen management (data not shown) or seed selection resulted in greater yield loss under highly disease conducive

\section{A}

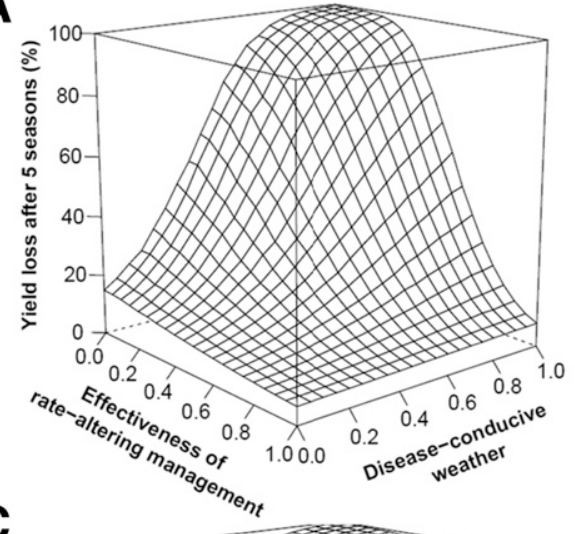

C

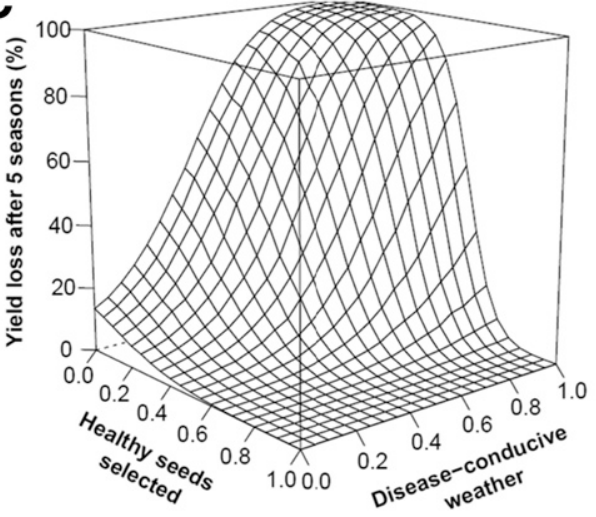

B

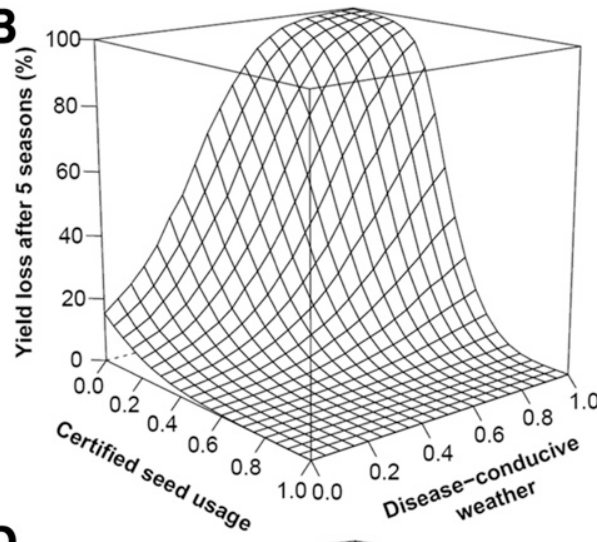

D

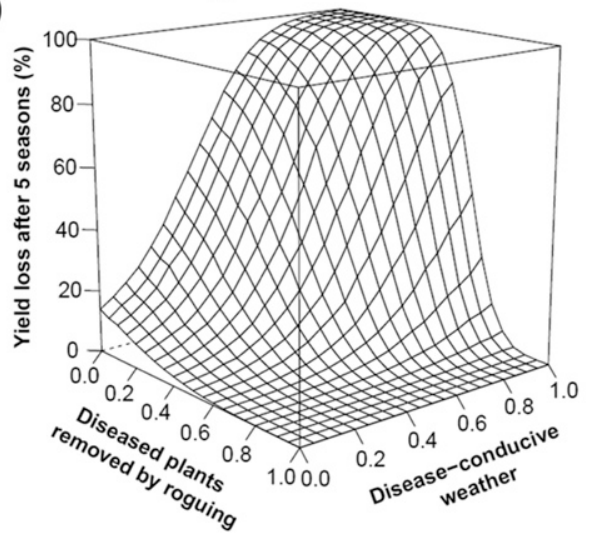

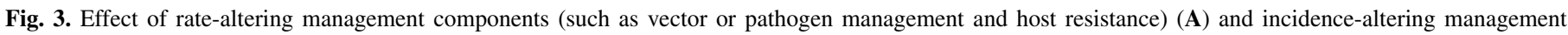

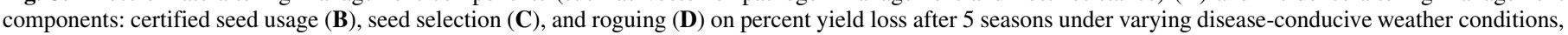

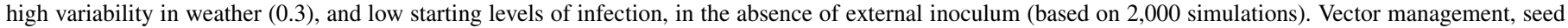

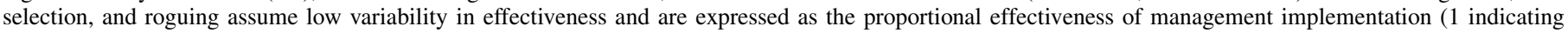
complete effectiveness, and 0 indicating no management). Other parameters were set to the default values in Table 2 .

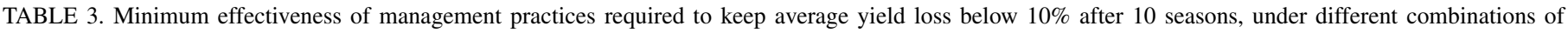
weather conduciveness, host resistance, and low starting levels of infection, in the absence of external inoculum (based on 2,000 simulations) ${ }^{\mathrm{a}}$

\begin{tabular}{|c|c|c|c|c|c|}
\hline \multirow[b]{2}{*}{ Management practice } & \multicolumn{2}{|c|}{$\begin{array}{l}\text { Highly disease- } \\
\text { conducive weather }\end{array}$} & \multicolumn{2}{|c|}{$\begin{array}{l}\text { Marginally disease- } \\
\text { conducive weather }\end{array}$} & \multirow[b]{2}{*}{ Interpretation } \\
\hline & $\begin{array}{l}\text { Susceptible } \\
\text { host }\end{array}$ & $\begin{array}{l}\text { Resistant } \\
\text { host }\end{array}$ & $\begin{array}{l}\text { Susceptible } \\
\text { host }\end{array}$ & $\begin{array}{c}\text { Resistant } \\
\text { host }\end{array}$ & \\
\hline Vector or pathogen management & 0.9 & 0.7 & 0.7 & 0.0 & Proportional effectiveness of vector or pathogen management \\
\hline Roguing & 0.7 & 0.4 & 0.3 & 0.0 & Proportion diseased plants removed \\
\hline Seed selection & 0.7 & 0.4 & 0.3 & 0.0 & Proportion healthy seed selected \\
\hline Use of certified seed & 0.6 & 0.3 & 0.3 & 0.1 & Proportion certified seed used for planting \\
\hline
\end{tabular}

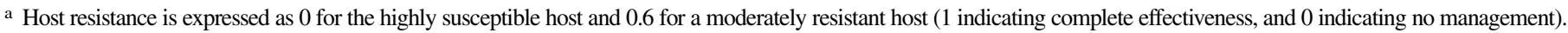
For each of the other management components tested, a range of values from 0 to 1 at increments of 0.1 was evaluated. Other parameters had default values from Table 2 . 
weather conditions (Fig. 5). In marginally disease-conducive weather $(<0.2)$ and low proportional effectiveness of implementing seed selection $(<0.2)$, high variability in selection (Fig. 5B, D) resulted in lower yield loss than low variability scenarios (Fig. $5 \mathrm{~A}, \mathrm{C})$. This was because, given the model structure, at low effectiveness of implementation, variability resulted in a higher proportion of healthy plants being incorporated. Conversely, under high effectiveness of implementation, variability in selection resulted in the incorporation of more diseased plants. These trends were more predominant when the starting infection levels were high (Fig. 5C, D).

Season-to-season variability in weather and management practices resulted in variable levels of yield loss (Table 5). In addition to the mean outcomes, we considered the near worst-case outcomes (95th percentile) and the near best-case outcomes (fifth percentile). In the near best-case outcome, by implementing seed selection at 0.6 proportional effectiveness for a variety with resistance at level 0.6 out of 1.0, a farmer incurred a yield loss of $16 \%$ under highly disease-conducive weather conditions, in the presence of external inoculum (Table 5). However, in the worst-case outcome, implementing management components at the same level of effectiveness resulted in 50\% yield loss (Table 5). In the absence of external inoculum, combining seed selection and host resistance resulted in $<5 \%$ yield loss in best-, worst-case, and average outcomes (Table 5).

Use of expert elicitation to provide input for cropspecific analyses. In the absence of information about geographic deployment of resistance in cassava, each level of resistance might be considered equally likely, as in an uninformative prior in Bayesian analysis. For a uniform distribution of resistance deployment, model predictions for yield loss in a region would be considerably lower than are likely to be observed, given the rarity of resistance deployment reported in expert elicitation. Crop-specific acreage information obtained from experts (Fig. 6A) can be used to estimate regional yield loss. The resulting modified yield loss distribution (Fig. 6C) is one step more realistic for cassava in Africa and India, in this illustration for marginally disease-conducive weather scenarios.

\section{DISCUSSION}

The seed degeneration risk assessment framework was designed to identify scenarios for low-income countries where on-farm management components may be useful, and where they may be absolutely necessary to slow or reverse seed degeneration. Although substantial data collection would be necessary to estimate parameter values in the model for a particular crop, pathogen, and geographic region, this general model (where the model structure draws on current theoretical understanding of seed degeneration [Holt et al. 1997; McQuaid et al. 2016; van den Bosch et al. 2007]) allows us to identify broad implications for the management of seed degeneration. We observed that:

1. On-farm seed selection can perform as well as certified seed use, if the rate of success in selecting healthy plants is high.
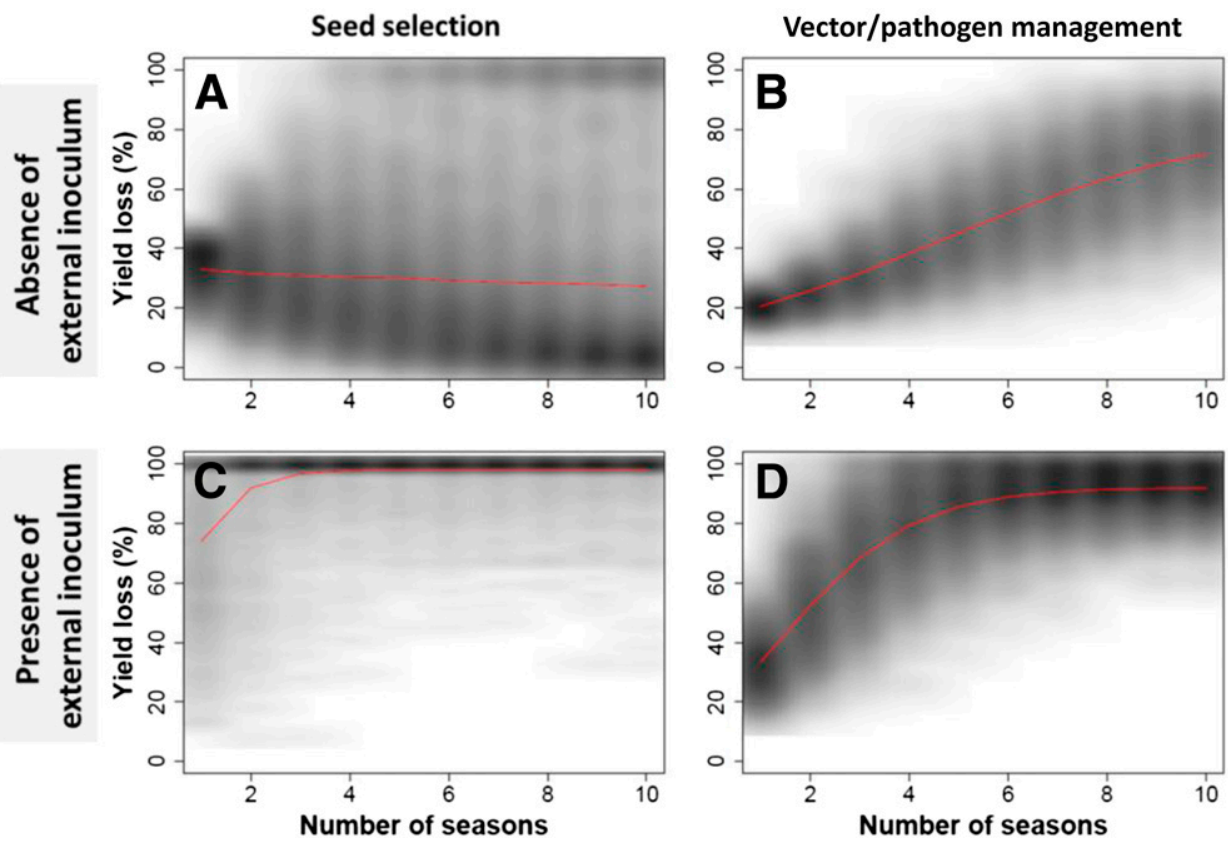

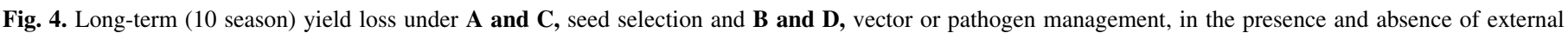

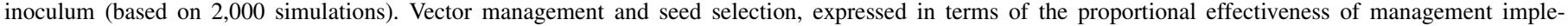

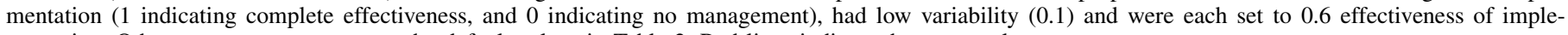
mentation. Other parameters were set to the default values in Table 2. Red lines indicate the mean values.

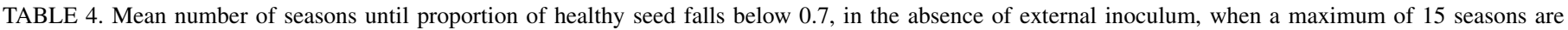
considered (based on 2,000 simulations) ${ }^{\mathrm{a}}$

\begin{tabular}{|c|c|c|c|c|c|}
\hline \multirow{2}{*}{\multicolumn{2}{|c|}{$\begin{array}{c}\text { Proportional effectiveness of } \\
\text { management }\end{array}$}} & \multicolumn{2}{|c|}{ Highly disease-conducive weather } & \multicolumn{2}{|c|}{ Marginally disease-conducive weather } \\
\hline & & \multirow{2}{*}{$\begin{array}{c}\text { Absence of } \\
\text { external inoculum }\end{array}$} & \multirow{2}{*}{$\begin{array}{c}\text { Presence of } \\
\text { external inoculum }\end{array}$} & \multirow{2}{*}{$\begin{array}{c}\text { Absence of } \\
\text { external inoculum }\end{array}$} & \multirow{2}{*}{$\begin{array}{l}\text { Presence of } \\
\text { external inoculum }\end{array}$} \\
\hline Seed selection & Host resistance & & & & \\
\hline 0 & 0 & 1.2 & 1.0 & 6.1 & 2.1 \\
\hline 0.6 & 0 & 11.6 & 1.2 & $>15.0$ & 8.6 \\
\hline 0 & 0.6 & 3.1 & 1.2 & 14.9 & 5.6 \\
\hline 0.6 & 0.6 & $>15.0$ & 11.6 & $>15.0$ & $>15.0$ \\
\hline
\end{tabular}

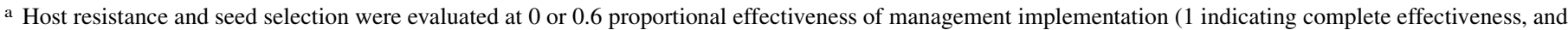
0 indicating no management). Other parameters had the default values from Table 2. 
Using the risk assessment framework for seed degeneration, we illustrate how roguing and seed selection can perform as well as use of certified seed (Fig. 3). However, for many pathosystems, achieving a suitably high rate of success in symptom recognition is challenging when symptoms are cryptic or variable. If the effectiveness of implementation is low, high yield loss may result despite practicing seed selection (Fig. 5D). For cassava seed degeneration caused by CBSD, above-ground symptoms are cryptic (Legg et al. 2011), while for cassava mosaic disease (CMD), symptom expression is much more reliable but depends partially on seasonal weather conditions (Gibson and Otim-Nape 1997). The usefulness of seed selection has been demonstrated for some diseases. For viral diseases and bacterial wilt in potato, farmer-managed trials of seed selection resulted in a $\sim 30 \%$ yield increase, with lower disease incidence (Gildemacher et al. 2011; Schulte-Geldermann et al. 2012). Seed selection also increased the tuberous root yields of CMD-susceptible cassava varieties (Mallowa et al. 2006). In parts of western Kenya where CMD is in its post epidemic phase, there is a resurgence of local landraces that are CMD-susceptible, partly because farmers choose the most vigorous plants as seed sources (Mallowa et al. 2006). Farmers may decide against roguing when diseased plants produce usable yield, limiting the practical usefulness of roguing (Legg et al. 2015; Mallowa et al. 2011; Sisterson and Stenger 2013). Under such situations, restricting roguing to early in the season (Supplementary Material S3) and coordinating roguing over regional scales (Sisterson and Stenger 2013) can increase the benefits and potentially the incentives for roguing. Additionally, the model treats certified seed material as completely disease-free. Deep-sequencing techniques have revealed that many plant viruses are yet to be described (Kreuze et al. 2009). Thus, accurate certification depends on diagnostic accuracy and the characterization of a crop virome that can evolve over time and is currently unstudied for crops in many geographic regions. Finally, it is important to remember that, in many low-income countries, farmers have limited or no access to certified seed, and seed selection with even suboptimum efficiency may provide yield benefits (Holt et al. 1997).

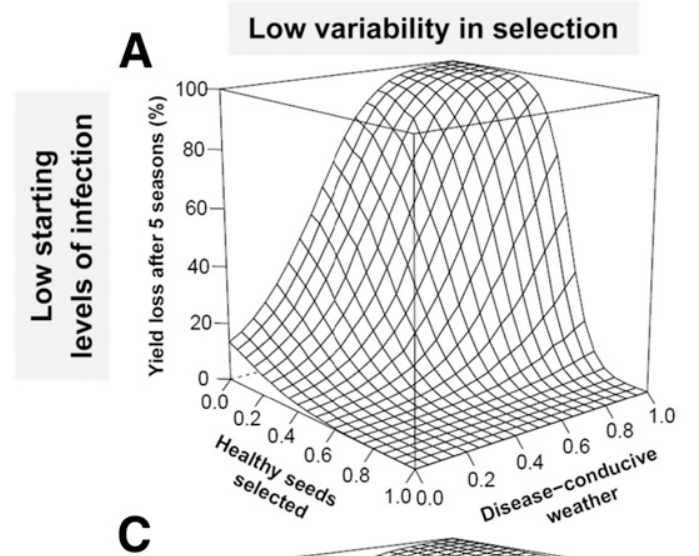

\section{B High variability in selection}
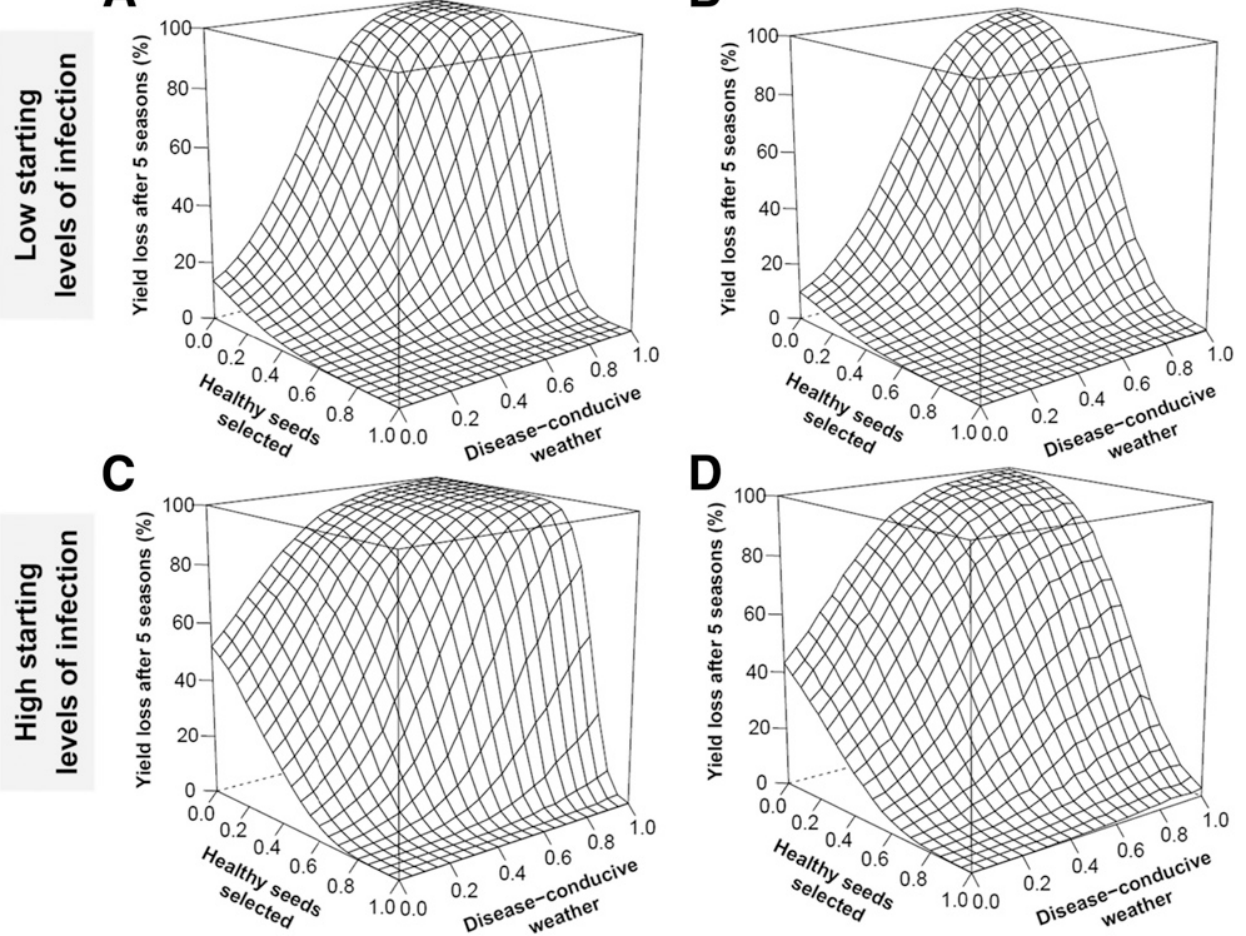

Fig. 5. Percent yield loss after 5 seasons as a function of the mean effectiveness of seed selection (proportion healthy seeds selected) for the range of potential levels of disease-conduciveness of weather, at low $(\mathbf{A}, \mathbf{B})$ and high $(\mathbf{C}, \mathbf{D})$ starting levels of infection, and low $(0.1 ; \mathbf{A}, \mathbf{C})$ and high $(0.3 ; \mathbf{B}, \mathbf{D})$ variability in selection, in the absence of external inoculum (based on 2,000 simulations). Seed selection is expressed in terms of the proportional effectiveness of management implementation ( 1 indicating complete effectiveness, and 0 indicating no management). Other parameters were set to the default values in Table 2.

TABLE 5. Yield loss incurred for average, near worst-case, and near best-case outcomes when seed selection and host resistance are used at 0.6 effectiveness of implementation, under highly disease-conducive weather conditions (based on 2,000 simulations) ${ }^{\mathrm{a}}$

\begin{tabular}{|c|c|c|c|c|c|c|c|}
\hline \multirow{2}{*}{\multicolumn{2}{|c|}{$\begin{array}{c}\text { Proportional effectiveness of } \\
\text { management }\end{array}$}} & \multicolumn{3}{|c|}{ Absence of external inoculum } & \multicolumn{3}{|c|}{ Presence of external inoculum } \\
\hline & & \multirow{2}{*}{$\begin{array}{l}5 \text { th percentile (near } \\
\text { best-case outcome) }\end{array}$} & \multirow[b]{2}{*}{ Mean outcome } & \multirow{2}{*}{$\begin{array}{l}\text { 95th percentile (near } \\
\text { worst-case outcome) }\end{array}$} & \multirow{2}{*}{$\begin{array}{l}5 \text { th percentile (near } \\
\text { best-case outcome) }\end{array}$} & \multirow[b]{2}{*}{ Mean outcome } & \multirow{2}{*}{$\begin{array}{l}\text { 95th percentile (near } \\
\text { worst-case outcome) }\end{array}$} \\
\hline Seed selection & Host resistance & & & & & & \\
\hline 0 & 0 & 89 & 98 & 100 & 95 & 99 & 100 \\
\hline 0 & 0.6 & 25 & 42 & 56 & 65 & 85 & 97 \\
\hline 0.6 & 0.6 & 1 & 2 & 4 & 16 & 31 & 50 \\
\hline
\end{tabular}

${ }^{a}$ Host resistance and seed selection were evaluated at 0 and 0.6 proportional effectiveness of management implementation (1 indicating complete effectiveness, and 0 indicating no management). Other parameters had the default values in Table 2. 
2. When choosing among within-season management components, external inoculum can determine the relative usefulness of incidence- and rate-altering management. Management practices such as vector or pathogen management and host resistance can be particularly useful when external inoculum is high and plants are potentially at risk of rapid infection from surrounding fields (Fig. 4). In sweetpotato, the proximity and level of inoculum in surrounding fields (a function of the level of host resistance in surrounding fields) can affect the incidence of sweetpotato viral disease (Aritua et al. 1999). Fargette and Vie (1995) suggested that phytosanitation (by selection of cuttings and roguing) would be more useful in areas with high inoculum levels or susceptible cultivars, because under low inoculum pressure, the use of resistant cultivars with reversion would sufficiently manage the disease. However, where local inoculum levels are very high, plants would quickly become infected, making selection of cuttings and roguing less feasible. In our evaluation, under low external inoculum (e.g., when crop fields are isolated from each other), and when $10 \%$ of the cuttings underwent reversion, incidence-altering management was better for managing degeneration than ratealtering management strategies. In post CMD epidemic areas (where there is reduced inoculum), seed selection along with reversion and natural cross protection by mild viruses together allow farmers to cultivate locally preferred, CMDsusceptible varieties (Mallowa et al. 2006).

3. For severe disease scenarios, when implementing management components at high levels of effectiveness is difficult, combining management components can produce synergistic benefits and keep seed degeneration below a threshold. For Potato leafroll virus (PLRV) management, the threshold at which vector management becomes necessary may be modified by using resistant varieties (DiFonzo et al. 1995). Our study illustrates how the time until renewal with certified seed was needed was prolonged when seed selection and host resistance were applied together (Table 4). In the presence of external inoculum, it is particularly clear that the performance of the combined strategy would be greater than the combination of simple additive effects of individual components, demonstrating potential synergy. We make a simplifying assumption that the time until renewal with certified seed, and the choice of how to integrate management components, depends solely on yield loss. In reality, many socioeconomic factors such as cost and incentives for management, stakeholder preferences, positions in socioeconomic networks, etc., should also be considered to better understand the factors affecting renewal with certified seed, and adoption rates of integrated management practices more broadly in low-income countries (Andersen et al. 2017; Hernandez Nopsa et al. 2017; Parsa et al. 2014).

4. Combining management components can close the yield gap between average and near worst-case outcomes caused by weather and management heterogeneity. In the context of development, there may be particular concern for the worstcase outcomes, such as when particularly disease-conducive years may drive vulnerable farmers out of business. High seasonal fluctuations in weather in a geographic region can result in very high yield reductions in the long term, despite a region being marginally disease-conducive on average (Fig. 2). The increased frequency of extreme weather is predicted in many climate change scenarios and can lower the performance of disease management practices (Garrett et al. 2013; Jones 2016; Lamichhane et al. 2015). McQuaid et al. (2016) report scenario analyses where, to keep CBSD infection below $10 \%$ in seed farms located in areas with lower inoculum pressure, roguing needed to be conducted frequently (weekly or fortnightly intervals) and at a relatively high success rate (70\% or higher). Roguing susceptible varieties can however significantly reduce yields compared with a 'do nothing' strategy, largely due to the elimination of plant populations (Mallowa et al. 2011). In such cases where farmers are hesitant to remove plants or have difficulty recognizing cryptic symptoms (Legg et al. 2011), infection rates may become too high for roguing or seed selection to be successful. Yield losses can be much higher for near-worst case outcomes than average outcomes, but can be improved by combining management practices (Table 5).

A Mean of experts' estimate of cassava field acreage under different resistance levels

\begin{tabular}{ccccccccccc}
\multicolumn{4}{c}{$\begin{array}{c}0=\text { varieties grown are } \\
\text { susceptible }\end{array}$} & & & \multicolumn{4}{c}{$\begin{array}{c} \\
\text { varieties grown are } \\
\text { immune }\end{array}$} \\
\hline $\begin{array}{c}\text { Resistance } \\
\text { levels }\end{array}$ & $0-10$ & $11-20$ & $21-30$ & $31-40$ & $41-50$ & $51-60$ & $61-70$ & $71-80$ & $81-90$ & $91-100$ \\
\hline $\begin{array}{c}\text { Field } \\
\text { acreage }\end{array}$ & 38.75 & 22.5 & 0 & 5 & 3.75 & 0 & 21.25 & 0 & 7.5 & 1.25
\end{tabular}

No information on resistance deployment With expert elicited information
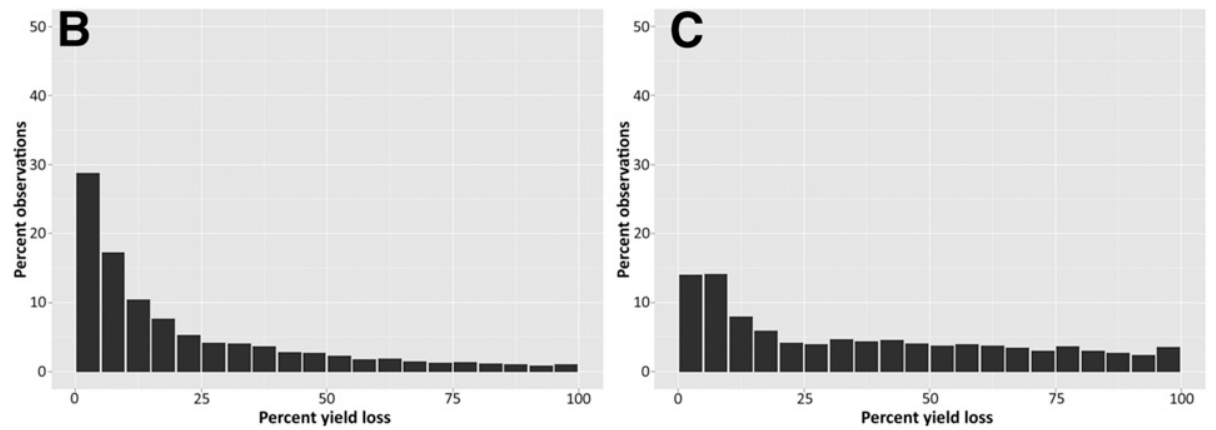

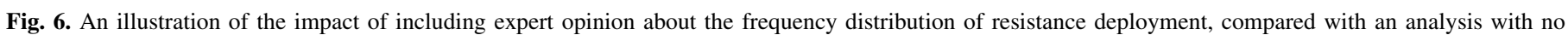

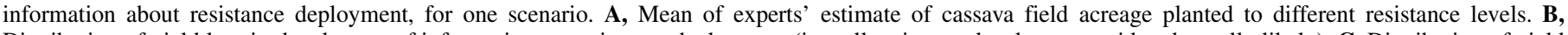

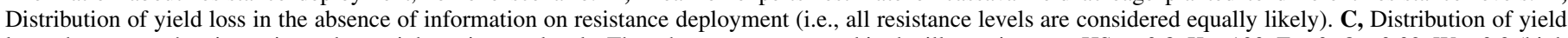

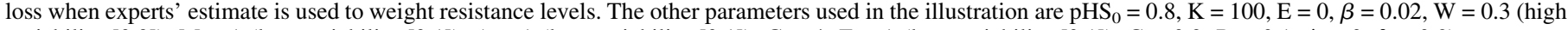
variability [0.3]), $\mathrm{M}=1$ (low variability [0.1]), $\mathrm{A}=1$ (low variability $[0.1]$ ), $\mathrm{G}=4, \mathrm{Z}=1$ (low variability $[0.1]$ ), $\mathrm{C}=0.9, \mathrm{R}=0.1, \phi=0, \theta=0.2$ ). 
This risk assessment framework for seed degeneration was designed to capture season-to-season dynamics of degeneration, so the model aggregates within-season characteristics of degeneration in most analyses. The model defines degeneration as an increase in incidence of infected seed in the seed lot and does not capture an increase in pathogen load (e.g., virus titer) within a plant. Other specific attributes of vectors such as inoculation efficiency, acquisition efficiency, vector birth/death rates, etc., that are relevant at finer temporal resolution, have been aggregated in the maximum seasonal transmission rate $(\beta)$ and the parameters that modify it. Thus, when calibrating the model for application to a particular crop species in a particular location, developing good estimates of $\beta$ and modifying parameters will be a key step.

Another goal of this risk assessment framework for seed degeneration is flexibility in adapting to the study of different pathogens causing seed degeneration. Although viruses are a major cause of seed degeneration in many crops, in West African yam, the nematodes Scutellonema bradys, Pratylenchus coffeae, and Meloidogyne spp. are major causes of degeneration (Coyne et al. 2010). In bananas grown in Africa, many nematodes (e.g., Radopholus similis and $P$. coffeae) and bacterial pathogens (e.g., Xanthomonas campestris pv. musacearum) readily accumulate and spread via planting material (Blomme et al. 2014). In general, $\beta$ may be substantially higher for vector-borne viruses compared with soilborne pathogens. Also, the weather index directly modifies $\beta$ and may be conceptualized as directly affecting pathogens, or the dynamics of virus vectors. The potential effectiveness of implementation of management components may vary widely for management of vectors, fungi, bacteria, and nematodes, and can be modified accordingly. Interactions between pathogens that result in exacerbation of symptoms and increased disease spread would require modification of both $\beta$ and the effectiveness of symptombased management (Hilker et al. 2017).

We used expert elicitation to obtain parameter estimates for use in the seed degeneration risk assessment model. Although expert elicitation cannot replace empirical experimentation, we were interested in exploring expert elicitation as a tool to characterize the frequency of different cropping scenarios in a region, which can then be updated as more direct observations become available. A limitation of data from expert elicitation is its subjective nature, potentially influenced by biases. Using data from expert elicitation, we were able to evaluate the relative effects of management components at a regional scale, taking into account expert estimates of how commonly and with what level of effectiveness the management components were implemented.

This seed degeneration risk assessment framework was designed to answer general questions about the relative performance of management components, alone and in combination, and to provide a platform to answer 'what-if' questions for specific scenarios of a crop, pathosystem, and geographic region. For any given pathosystem, implementing the framework can also help to identify key gaps in current knowledge, where parameter estimates are difficult to obtain, that could be the focus of future field studies (Restif et al. 2012). For example, the regional conduciveness of weather to disease could be evaluated based on general observations of regional disease severity, keeping in mind that crop host availability can also be a limiting factor for disease. If good models of weather effects on vector or pathogen dynamics are available, these could be used to evaluate disease-conduciveness in a more flexible way, with more potential to study the effects of weather variability and climate change, and to partition the effects of weather and host abundance. As data sets and parameter estimates for a particular pathosystem become available from field studies, the performance of the model framework can be evaluated to see if the model structure should be modified. A more pathosystem-specific version of the model can be used to answer questions about the time until renewal with certified seed becomes necessary, and how effectively management components have to be implemented to keep yield loss below a threshold. Ongoing work with the framework is aimed at expanding it to a regional scale in addition to analysis of individual fields, through added information from the literature, new field studies, and expert elicitation. Individual growers act in networks, within which they intentionally and unintentionally exchange information, seed, and pathogens (Garrett 2012; MoslonkaLefebvre et al. 2011; Shaw and Pautasso 2014). Evaluating the structure of regional networks for the movement of seed may help in targeting where extension and mitigation are most important (Andersen et al. 2017; Hernandez Nopsa et al. 2015, 2017), and may also help to address the challenge of understanding the role of external inoculum in disease risk within a field. Network concepts may also be extended to consider how landscape structures create links among host species (Cox et al. 2013), an important factor for generalist pathogens and vectors. Another important outcome of a regional framework would be regional or larger-extent maps of the likely performance of different seed degeneration management strategies, as an extension of concepts in species distribution mapping (Franklin 2009). Maps of likely management performance can help to inform prioritization by policy makers and extension groups.

\section{ACKNOWLEDGMENTS}

We appreciate very helpful input from Phytopathology reviewers. KAG, STS, and GAF developed the framework and model with input from all authors. STS and KAG wrote the R code. STS performed the computational experiments. STS interviewed experts for the expert elicitation component. STS, KAG, and GAF wrote the manuscript with input from all authors. This work was supported by the CGIAR Research Program on Roots, Tubers, and Bananas, the CGIAR Research Program on Climate Change, Agriculture and Food Security, the Kansas Agricultural Experiment Station, an NSF-BMGF BREAD Idea Challenge Award to STS, US NSF Grant EF-0525712 as part of the joint NSF-NIH Ecology of Infectious Disease program, US NSF Grant DEB-0516046, the National Institute for Mathematical and Biological Synthesis (NIMBioS), and the University of Florida. We thank scientists at the following institutions for their participation in the expert elicitation study: Central Tuber Crop Research Institute, Thiruvananthapuram, India; Banana Research Station, Kannara, India; Kerala Agricultural University (KAU), Thrissur, India; KAU, Thiruvananthapuram, India; National Research Center for Banana, Tiruchirapalli, India; International Institute of Tropical Agriculture (IITA), Dar es Salam, Tanzania; IITA Ibadan, Nigeria; University of Queensland, Brisbane, Australia; International Potato Center (CIP), Quito, Ecuador; CIP, Lima, Peru; CIP, Beijing, China; and Indian Agricultural Research Institute, New Delhi, India.

\section{LITERATURE CITED}

Andersen, K. F., Buddenhagen, C. E., Rachkara, P., Gibson, R., Kalule, S., Phillips, D., and Garrett, K. A. 2017. Analyzing key nodes and epidemic risk in seed networks: Sweetpotato in Northern Uganda. bioRxiv (preprint). Online: https://doi.org/10.1101/107359

Aritua, V., Legg, J. P., Smit, N., and Gibson, R. W. 1999. Effect of local inoculum on the spread of sweet potato virus disease: limited infection of susceptible cultivars following widespread cultivation of a resistant sweet potato cultivar. Plant Pathol. 48:655-661.

Berger, R. D. 1977. Application of epidemiological principles to achieve plant disease control. Annu. Rev. Phytopathol. 15:165-183.

Bertschinger, L. 1992. Modelling of potato virus pathosystems by means of quantitative epidemiology. PhD thesis. Swiss Federal Institute of Technology, Zurich, Switzerland.

Bertschinger, L., Keller, E. R., and Gessler, C. 1995. Characterization of the virus $\times$ temperature interaction in secondarily infected potato plants using EPIVIT. Phytopathology 85:815-819.

Blomme, G., Jacobsen, K., Ocimati, W., Beed, F., Ntamwira, J., Sivirihauma, C., Ssekiwoko, F., Nakato, V., Kubiriba, J., Tripathi, L., Tinzaara, W., Mbolela, F., Lutete, L., and Karamura, E. 2014. Fine-tuning banana Xanthomonas wilt control options over the past decade in East and Central Africa. Eur. J. Plant Pathol. 139:271-287.

Carvajal-Yepes, M., Olaya, C., Lozano, I., Cuervo, M., Castano, M., and Cuellar, W. J. 2014. Unraveling complex viral infections in cassava (Manihot esculenta Crantz) from Colombia. Virus Res. 186:76-86. 
Cox, C. M., Bockus, W. W., Holt, R. D., Fang, L., and Garrett, K. A. 2013. Spatial connectedness of plant species: potential links for apparent competition via plant diseases. Plant Pathol. 62:1195-1204.

Coyne, D. L., Claudius-Cole, A. O., Kenyon, L., and Baimey, H. 2010. Differential effect of hot water treatment on whole tubers versus cut setts of yam (Dioscorea spp.). Pest Manag. Sci. 66:385-389.

DiFonzo, C. D., Ragsdale, D. W., and Radcliffe, E. B. 1995. Potato leafroll virus spread in differentially resistant potato cultivars under varying aphid densities. Am. Potato J. 72:119-132.

Fankhauser, C. 2000. Seed-transmitted diseases as constraints for potato production in the tropical highlands of Ecuador. PhD thesis. Swiss Federal Institute of Technology, Zurich, Switzerland.

Fargette, D., Colon, L. T., Bouveau, R., and Fauquet, C. 1996. Components of resistance of cassava to African cassava mosaic virus. Eur. J. Plant Pathol. 102:645-654.

Fargette, D., and Vie, K. 1995. Simulation of the effects of host resistance, reversion, and cutting selection on incidence of African cassava mosaic virus and yield losses in cassava. Phytopathology 85:370-375.

Franklin, J. 2009. Mapping species distributions: spatial inference and prediction. Cambridge University Press, Cambridge, U.K.

Frost, K. E., Groves, R. L., and Charkowski, A. O. 2013. Integrated control of potato pathogens through seed potato certification and provision of clean seed potatoes. Plant Dis. 97:1268-1280.

Garrett, K. A. 2012. Information networks for disease: commonalities in human management networks and within-host signalling networks. Eur. J. Plant Pathol. 133:75-88.

Garrett, K. A., Dobson, A. D. M., Kroschel, J., Natarajan, B., Orlandini, S., Tonnang, H. E. Z., and Valdivia, C. 2013. The effects of climate variability and the color of weather time series on agricultural diseases and pests, and decision-making for their management. Agric. For. Meteorol. 170: 216-227.

Gergerich, R. C., Welliver, R. A., Gettys, S., Osterbauer, N. K., Kamenidou, S., Martin, R. R., Golino, D. A., Eastwell, K., Fuchs, M., Vidalakis, G., and Tzanetakis, I. E. 2015. Safeguarding fruit crops in the age of agricultural globalization. Plant Dis. 99:176-187.

Gibson, R. W., and Otim-Nape, G. W. 1997. Factors determining recovery and reversion in mosaic-affected African cassava mosaic virus resistant cassava. Ann. Appl. Biol. 131:259-271.

Gibson, R. W., and Kreuze, J. F. 2014. Degeneration in sweetpotato due to viruses, virus-cleaned planting material and reversion: a review. Plant Pathol. 64:1-15

Gibson, R. W., Wasswa, P., and Tufan, H. A. 2014. The ability of cultivars of sweetpotato in East Africa to 'revert' from Sweet potato feathery mottle virus infection. Virus Res. 186:130-134.

Gildemacher, P. R., Demo, P., Barker, I., Kaguongo, W., Woldegiorgis, G., Wagoire, W. W., Wakahiu, M., Leeuwis, C., and Struik, P. C. 2009. A description of seed potato systems in Kenya, Uganda and Ethiopia. Am. J. Potato Res. 86:373-382.

Gildemacher, P. R., Schulte-Geldermann, E., Borus, D., Demo, P., Kinyae, P., Mundia, P., and Struik, P. C. 2011. Seed potato quality improvement through positive selection by smallholder farmers in Kenya. Potato Res. 54: 253-266.

Grimm, V., Berger, U., DeAngelis, D. L., Polhill, J. G., Giske, J., and Railsback, S. F. 2010. The ODD protocol: a review and first update. Ecol. Modell. 221:2760-2768.

Gross, L. J. 2013. Use of computer systems and models. Pages 213-220 in: Encyclopedia of Biodiversity, 2nd Ed., S. A. Levin, ed. Vol. 2. Academic Press, Waltham, MA.

Hernandez Nopsa, J. F., Buddenhagen, C. E., Andersen, K. F., Andrade-Piedra, J., Forbes, G. A., Kromann, P., Thomas-Sharma, S., Useche, P., and Garrett, K. A. 2017. Epidemic network analysis for mitigation of invasive pathogens in seed systems: Potato in Ecuador. bioRxiv (preprint). Online: https://doi. org/10.1101/107367.

Hernandez Nopsa, J. F., Daglish, G. J., Hagstrum, D. W., Leslie, J. F., Phillips, T. W., Scoglio, C., Thomas-Sharma, S., Walter, G. H., and Garrett, K. A. 2015. Ecological networks in stored grain: Key postharvest nodes for emerging pests, pathogens, and mycotoxins. BioScience 65: 985-1002.

Hilker, F. M., Allen, L. J. S., Bokil, V. A., Briggs, C. J., Feng, Z., Garrett, K. A., Gross, L. J., Hamelin, F. M., Jeger, M. J., Manore, C. A., Power, A. G., Redinbaugh, M. G., Rúa, M. A., and Cunniffe, N. J. 2017. Modelling virus coinfection to inform management of maize lethal necrosis in Kenya. Phytopathology 107:1095-1108.

Holt, J., Jeger, M. J., Thresh, J. M., and Otim-Nape, G. W. 1997. An epidemiological model incorporating vector population dynamics applied to African cassava mosaic virus disease. J. Appl. Ecol. 34:793-806.

Hughes, G., and Madden, L. V. 2002. Some methods for eliciting expert knowledge of plant disease epidemics and their application in cluster sampling for disease incidence. Crop Prot. 21:203-215.
Jones, R. A. C. 2006. Control of plant virus diseases. Adv. Virus Res. 67: 205-244

Jones, R. A. C. 2016. Future scenarios for plant virus pathogens as climate change progresses. Adv. Virus Res. 95:87-147.

Knol, A. B., Slottje, P., van der Sluijs, J. P., and Lebret, E. 2010. The use of expert elicitation in environmental health impact assessment: a seven step procedure. Environ. Health 9:19.

Kreuze, J. F., Perez, A., Untiveros, M., Quispe, D., Fuentes, S., Barker, I., and Simon, R. 2009. Complete viral genome sequence and discovery of novel viruses by deep sequencing of small RNAs: A generic method for diagnosis, discovery and sequencing of viruses. Virology 388:1-7.

Lamichhane, J. R., Barzman, M., Booij, K., Boonekamp, P., Desneux, N., Huber, L., Kudsk, P., Langrell, S. R. H., Ratnadass, A., Ricci, P., Sarah, J.-L., and Messean, A. 2015. Robust cropping systems to tackle pests under climate change. A review. Agron. Sustain. Dev. 35:443-459.

Legg, J. 1999. Emergence, spread and strategies for controlling the pandemic of cassava mosaic virus disease in east and central Africa. Crop Prot. 18: 627-637.

Legg, J. P., Jeremiah, S. C., Obiero, H. M., Maruthi, M. N., Ndyetabula, I., Okao-Okuja, G., Bouwmeester, H., Bigirimana, S., Tata-Hangy, W., Gashaka, G., Mkamilo, G., Alicai, T., and Kumar, P. L. 2011. Comparing the regional epidemiology of the cassava mosaic and cassava brown streak virus pandemics in Africa. Virus Res. 159:161-170.

Legg, J. P., Kumar, P. L., Makeshkumar, T., Tripathi, L., Ferguson, M., Kanju, E., Ntawuruhunga, P., and Cuellar, W. 2015. Cassava virus diseases: Biology, epidemiology, and management. Adv. Virus Res. 91:85-142.

Levins, R. 1966. The strategy of model building in population biology. Am. Sci. 54:421-431

Mac Nally, R. 2007. Consensus weightings of evidence for inferring breeding success in broad-scale bird studies. Austral Ecol. 32:479-484.

Mallowa, S. O., Isutsa, D. K., Kamau, A. W., and Legg, J. P. 2011. Effectiveness of phytosanitation in cassava mosaic disease management in a post-epidemic area of western Kenya. ARPN J. Ag. Bio. Sci. 6:8-15.

Mallowa, S. O., Isutsa, D. K., Kamau, A. W., Obonyo, R., and Legg, J. P. 2006. Current characteristics of cassava mosaic disease in postepidemic areas increase the range of possible management options. Ann. Appl. Biol. 149: 137-144.

Martin, T. G., Kuhnert, P. M., Mengersen, K., and Possingham, H. P. 2005. The power of expert opinion in ecological models using Bayesian methods: Impact of grazing on birds. Ecol. Appl. 15:266-280.

McGuire, S., and Sperling, L. 2016. Seed systems smallholder farmers use. Food Secur. 8:179-195

McQuaid, C. F., Sseruwagi, P., Pariyo, A., and van den Bosch, F. 2016. Cassava brown streak disease and the sustainability of a clean seed system. Plant Pathol. 65:299-309.

Moslonka-Lefebvre, M., Finley, A., Dorigatti, I., Dehnen-Schmutz, K., Harwood, T., Jeger, M. J., Xu, X., Holdenrieder, O., and Pautasso, M. 2011. Networks in plant epidemiology: From genes to landscapes, countries, and continents. Phytopathology 101:392-403.

Mwangi, J. K., Nyende, A. B., Demo, P., and Matiru, V. N. 2008. Detection of latent infection by Ralstonia solanacearum in potato (Solanum tuberosum) using stems instead of tubers. Afr. J. Biotechnol. 7:1644-1649.

Oberkampf, W. L., Helton, J. C., Joslyn, C. A., Wojtkiewicz, S. F., and Ferson, S. 2004. Challenge problems: uncertainty in system response given uncertain parameters. Reliab. Eng. Syst. Saf. 85:11-19.

Parsa, S., Morse, S., Bonifacio, A., Chancellor, T. C. B., Condori, B., Crespo-Perez, V., Hobbs, S. L. A., Kroschel, J., Ba, M. N., Rebaudo, F., Sherwood, S. G., Vanek, S. J., Faye, E., Herrera, M. A., and Dangles, O. 2014. Obstacles to integrated pest management adoption in developing countries. Proc. Natl. Acad. Sci. USA 111:3889-3894.

R Core Team. 2016. R: A language and environment for statistical computing. R Foundation for Statistical Computing, Vienna, Austria.

Rahman, M. S., and Akanda, A. M. 2008. Impact of PVY and PLRV on growth and yield of second generation seed potato. Bangl. J. Plant Pathol. 24:19-24.

Restif, O., Hayman, D. T. S., Pulliam, J. R. C., Plowright, R. K., George, D. B., Luis, A. D., Cunningham, A. A., Bowen, R. A., Fooks, A. R., O'Shea, T. J., Wood, J. L. N., and Webb, C. T. 2012. Model-guided fieldwork: practical guidelines for multidisciplinary research on wildlife ecological and epidemiological dynamics. Ecol. Lett. 15:1083-1094.

Salazar, L. F. 1996. Potato viruses and their control. International Potato Center, Lima, Peru.

Schulte-Geldermann, E., Gildemacher, P. R., and Struik, P. C. 2012. Improving seed health and seed performance by positive selection in three Kenyan potato varieties. Am. J. Potato Res. 89:429-437.

Shaw, M. W., and Pautasso, M. 2014. Networks and plant disease management: Concepts and applications. Annu. Rev. Phytopathol. 52: 477-493. 
Sisterson, M. S., and Stenger, D. C. 2013. Roguing with replacement in perennial crops: Conditions for successful disease management. Phytopathology 103:117-128.

Thiele, G. 1999. Informal potato seed systems in the Andes: Why are they important and what should we do with them? World Dev. 27: 83-99.

Thomas-Sharma, S., Abdurahman, A., Ali, S., Andrade-Piedra, J., Bao, S., Charkowski, A., Crook, D., Kadian, M., Kromann, P., Struik, P., Torrance, L., Garrett, K. A., and Forbes, G. A. 2016. Seed degeneration in potato: the need for an integrated seed health strategy to mitigate the problem in developing countries. Plant Pathol. 65:3-16. van den Bosch, F., Jeger, M. J., and Gilligan, C. A. 2007. Disease control and its selection for damaging plant virus strains in vegetatively propagated staple food crops; a theoretical assessment. P. Roy. Soc. B-Biol. Sci. 274: 11-18.

van der Waals, J. E., Kruger, K., Franke, A. C., Haverkort, A. J., and Steyn, J. M. 2013. Climate change and potato production in contrasting South African agro-ecosystems 3 . Effects on relative development rates of selected pathogens and pests. Potato Res. 56:67-84.

Yamada, K., Elith, J., McCarthy, M., and Zerger, A. 2003. Eliciting and integrating expert knowledge for wildlife habitat modelling. Ecol. Modell. 165:251-264. 